\title{
Effectiveness of Initial Transarterial Chemoembolization for Hepatocellular Carcinoma Among Medicare Beneficiaries
}

\author{
Hanna K. Sanoff, MDª, YunKyung Chang, $\mathrm{PhD}^{\mathrm{a}}$; Joseph M. Stavas, MDc; Til Stürmer, MD, PhD ${ }^{\mathrm{a}, \mathrm{d}}$; and \\ Jennifer Lund, $\mathrm{PhD}^{\mathrm{a}, \mathrm{d}}$
}

\begin{abstract}
Background: Optimal administration of transarterial chemoembolization (TACE), the standard approach for intermediate-stage hepatocellular carcinoma (HCC), requires clinical and technical expertise. We sought to evaluate whether TACE retains its effectiveness when administered across a broad range of health care settings. Furthermore, as the use of yttrium ${ }^{90}\left(\mathrm{Y}^{90}\right)$ radioembolization has been increasing, we explored the comparative effectiveness of $\mathrm{Y}^{90}$ as an alternative to TACE. Methods: Patients with HCC diagnosed from 2004 through 2009 treated initially with TACE or $Y^{90}$ were identified from the SEER-Medicare linkage. Key covariates included prediagnosis $\alpha$-fetoprotein (AFP) screening, complications of cirrhosis, and tumor extent. Effect of treatment, patient, and health care system factors on overall survival (OS) was evaluated using multivariable Cox proportional hazards. Stratified OS estimates are provided. Propensity score (PS) weighting was used to compare effectiveness of $Y^{90}$ with TACE. Results: Of 1528 patients who underwent intra-arterial embolization, 577 received concurrent chemotherapy (eg, TACE). Median OS was 21 months (95\% Cl, 18-23) following TACE and 9 months (95\% Cl, 1-41) following Y90. Refined survival estimates stratified by stage, AFP screening, and liver comorbidity are presented. The 90 -day mortality rate after TACE was $21 \%$ to $25 \%$ in patients with extrahepatic spread or vascular invasion. In the PS-weighted analysis, $Y^{90}$ was associated with inferior survival, with an adjusted hazard ratio of $1.39(95 \% \mathrm{Cl}, 1.02-1.90)$. Conclusions: The effectiveness of TACE is generalizable to Medicare patients receiving care in a variety of treatment settings. However, early posttreatment mortality is high in patients with advanced disease. We found no evidence of improved outcomes with $Y^{90}$ compared with TACE. Survival estimates from this large cohort can be used to provide prognostic information to patients considering palliative TACE. (J Natl Compr Canc Netw 2015;13:1102-1110)
\end{abstract}

\section{Background}

Hepatocellular carcinoma (HCC) is one of a handful of malignancies with increasing incidence and mortality rates in the United States. ${ }^{1,2}$ HCC has a very poor prognosis, largely because two-thirds of patients have underlying cirrhosis and most have multifocal cancer, both of which limit treatment options. ${ }^{2,3}$ Two intra-arterially delivered locoregional therapy (LRT) options are considered to be reasonable initial therapy for patients with unresectable HCC and compensated cirrhosis: transarterial chemoembolization (TACE) and yttrium ${ }^{90}\left(\mathrm{Y}^{90}\right)$ radioembolization. TACE delivers chemotherapy di-

From aUNC Lineberger Comprehensive Cancer Center and the bivision of Hematology/Oncology, 'Division of Vascular-Interventional Radiology, and dDepartment of Epidemiology, University of North Carolina, Chapel Hill, North Carolina.

Submitted March 11, 2015; accepted for publication July 7, 2015.

Dr. Sanoff receives research grants from Bayer and Novartis and has served as a consultant for Amgen. Dr. Stürmer receives salary support from the UNC Center of Excellence in Pharmacoepidemiology and unrestricted research grants from pharmaceutical companies (GlaxoSmithKline, Merck, and Sanofi-Aventis). The remaining authors have disclosed that they have no financial interests, arrangements, affiliations, or commercial interests rectly to the cancer through the hepatic arterial system with subsequent arterial embolization, or through the contemporary approach of concurrent chemotherapy delivery and embolization in the form of doxorubicineluting beads. Among patients with nonmetastatic HCC and compensated cirrhosis, TACE improves survival over supportive care ${ }^{4-6}$ and is widely considered the first-line treatment option. ${ }^{7}$ Bland embolization performed without chemotherapy is used for patients with less-compensated cirrhosis at some centers to minimize the risk of the procedure. Bland embolization seems to offer a less robust survival benefit. ${ }^{4}$

with the manufacturers of any products discussed in this article or their competitors.

This work was supported by grants from the National Cancer Institute, K07CA160722, to Dr. Sanoff, and the National Institute on Aging, R01AG023178, to Dr. Stürmer. Additional support was provided by the University Cancer Research Fund via the state of North Carolina to the Integrated Cancer Information and Surveillance System at UNC Lineberger Comprehensive Cancer Center.

These data were presented in part at the 2014 ASCO Annual Meeting. Correspondence: Hanna K. Sanoff, MD, University of North Carolina, Division of Hematology/Oncology, CB 7305, Chapel Hill, NC 27599.

E-mail: hanna_sanoff@med.unc.edu 
The optimal delivery of TACE requires considerable clinical expertise to appropriately select patients for therapy, and technical expertise for safe and effective administration. ${ }^{8}$ Therefore, TACE effectiveness might be diminished in centers without ready access to multidisciplinary clinical teams, including expert diagnostic and interventional radiology, hepatology, transplant surgery, and oncology. In a prior evaluation of HCC treatment and outcomes using the SEER-Medicare linkage of patients treated in the 1990s, outcomes following TACE were poor, with a median survival of less than 1 year. $^{9}$ A more recent SEER-Medicare analysis of patients treated from 2000 to 2005 also showed a short median survival of only 14 months. ${ }^{10}$ Both of these estimates were well below the quality metric of 20 months proposed by the Society of Interventional Radiology Standards of Practice Committee. ${ }^{8}$ However, as the more contemporary analysis excluded patients who underwent ablation, resection, or transplant at any time, only patients with the most advanced disease were evaluated. Therefore, we sought to evaluate the effectiveness of first-line TACE across the spectrum of cancer stages in a contemporary cohort.

$\mathrm{Y}^{90}$ radioembolization, in which either glass or resin microspheres laden with $\mathrm{Y}^{90}$ are delivered to cancers through the hepatic arteries, is emerging as an excellent TACE alternative as data have shown survival after $\mathrm{Y}^{90}$ to be comparable with that after TACE. ${ }^{11-21}$ With overlapping clinical indications and similar outcomes, both TACE and Y $^{90}$ are reasonable initial therapy choices for treating HCC in patients with compensated cirrhosis. However, the comparative effectiveness of these procedures as they are being administered throughout the United States is unknown. Therefore, using this large observational data set, we also sought to explore the comparative effectiveness of $\mathrm{Y}^{90}$ versus TACE.

\section{Patients and Methods}

\section{Study Population}

The cohort was derived from the SEER-Medicare linkage (described in detail elsewhere ${ }^{22,23}$ ). We included patients diagnosed with HCC from 2004 to 2009, excluding autopsy diagnoses. To avoid misclassification of liver metastases, patients with prior invasive cancer within 5 years were excluded. ${ }^{9}$ To ensure availability of claims, only patients with con- tinuous enrollment in Medicare Part A and Part B and those not enrolled in Medicare Managed Care in the 12 months before and after diagnosis (or death) were included. This analysis was deemed exempt from review by the Office of Human Research Ethics at the University of North Carolina (\#12-1828).

\section{Covariates}

Sociodemographic patient data, tumor size and number, and presence of macrovascular invasion were obtained from SEER (see supplemental eAppendix 1 , available with this article at JNCCN.org). Laboratory parameters were not available, and therefore diagnosis codes for complications of cirrhosis were used to control for confounding liver disease. ${ }^{24} \mathrm{HCC}$ screening behavior was ascertained based on prediagnosis $\alpha$-fetoprotein (AFP) $)^{25,26}$ as a surrogate measure of performance status, because use of cancer screening is associated with decreased probability of frailty in patients with cancer. ${ }^{27}$ The cause of liver disease was ascertained from claims using ICD-9 diagnosis codes for hepatitis B virus, hepatitis $\mathrm{C}$ virus, alcoholic cirrhosis, and other cirrhosis. Noncirrhotic comorbidity was determined using the Klabunde modification of the Charlson comorbidity index (CCI). ${ }^{28}$ All claims-based covariates were ascertained in the 12 months before diagnosis.

The treating hospital was defined for most patients from inpatient claims on the date of initial procedure. Hospital characteristics were derived from the SEER hospital file. Hospital volume was defined as LRT volume at the treating hospital in the 12 months preceding each individual patient's treatment.

\section{Treatment}

Treatment group was determined by initial therapy delivered. Codes for arterial occlusion without intraarterial radiotherapy were categorized as embolization (see supplemental eTable 1); those with codes for chemotherapy or intra-arterial chemotherapy delivery at the time of embolization were classified as chemoembolization (TACE) and those without as bland embolization (TAE). Because chemotherapy claims are reliable when present but are less wellidentified in records of hospitalized patients, ${ }^{29}$ some patients receiving chemoembolization were likely misclassified as receiving bland embolization. Because the intent of the procedure cannot be ascertained from claims, some patients classified as TAE 
may have received embolization for reasons other than anticancer therapy, such as to control bleeding from a ruptured tumor or in preparation for $\mathrm{Y}^{90}$ radioembolization that was subsequently aborted. There is no specific code for drug-eluting beads, thus we could not compare specific TACE strategies. Patients with codes for intra-arterial radiotherapy delivery were categorized as receiving $\mathrm{Y}^{90}$, regardless of embolization. Because preprocedure arterial embolization is required to ensure dose and safety of $\mathrm{Y}^{90}$, embolization codes in the 60 days before $Y^{90}$ administration were considered part of $\mathrm{Y}^{90}$.

\section{Statistical Analysis}

Overall survival (OS) was measured from date of initial procedure until death. Kaplan-Meier methods estimated OS for the entire cohort and within strata of tumor extent, liver comorbidity, and use of prediagnosis AFP screening. Cox proportional hazards models were used to evaluate factors associated with OS. Robust variances were used in all analyses.

Because TACE is the standard treatment, we also sought to determine what the effect of $\mathrm{Y}^{90}$ would be among patients typically treated with TACE by comparing the effectiveness of $\mathrm{Y}^{90}$ with TACE in a population of patients resembling those selected for initial TAE/TACE. To do so, a weighted pseudo-population was created from the propensity score (PS) for TAE/ TACE (see supplemental eAppendix 1 and eFigures 1 and 2). ${ }^{30}$ This created treatment groups balanced on key patient characteristics in which multivariable Cox proportional hazards models were used to adjust for residual covariate imbalances and OS was compared by treatment. In sensitivity analyses, we compared the effectiveness of $\mathrm{Y}^{90}$ versus TAE/TACE after restricting to only those TACE patients with codes for chemotherapy. We also conducted a PS-trimming sensitivity analysis to address the potential for unmeasured confounding by frailty. ${ }^{31}$ Because patients treated contrary to prediction are most likely to have unmeasured confounding that influences treatment selection (eg, frailty), omitting them may improve the validity of the treatment effect estimate. If the observed treatment effect were due to unmeasured confounding, it would be expected to approach the null with trimming. Because a larger proportion of TACE patients underwent subsequent curative surgery, sensitivity analysis explored the magnitude of this effect by censoring patients at the time of curative surgery.

\section{Results}

Initial LRT was administered to 1651 patients, including 1528 treated with TAE/TACE and 121 with first-line $\mathrm{Y}^{90}$ (Figure 1). Of patients treated with TAE/TACE, 577 (38\%) received TACE. The median age of the TAE/TACE group was 72 years (range 27-94 years), $66 \%$ of whom were white and $14 \%$ were Asian (Table 1). Most patients treated with TACE had liver-confined unifocal $(n=207 ; 42 \%)$ or multifocal $(n=207 ; 36 \%)$ disease without macrovascular invasion, although 126 patients $(22 \%)$ had either macrovascular invasion or extrahepatic disease. Second-line therapy was administered to 1010 patients $(66 \%)$ treated with TAE/TACE, including repeat TAE/TACE in $635(42 \%)$, curative surgery in $99(6 \%)$, ablation in $129(8 \%)$, and drug therapy in 104 (7\%) (see supplemental eTable 2). Many second procedures likely represent planned contralateral treatment, because 295 of 635 repeat TAE/TACEs occurred within 60 days of the first treatment.

\section{Survival After TACE}

The median survival in TACE patients was 21 months (95\% CI, 18-23), ranging from 24 months (95\% CI, 21-28) in patients with solitary tumors without vascular invasion to 11 months (95\% CI, 5-20) in patients with multiple tumors and vascular invasion. Ninety-day mortality was high in patients with extrahepatic spread $(25 \%)$ or multiple tumors with vascular invasion (21\%). Stratification by prediagnosis AFP screening and codes for liver comorbidity further refined these estimates (Table 2, Figure 2).

Patient sex, race/ethnicity, census tract median income, nonliver comorbidity, and cause of liver disease were not associated with survival (Table 1). Patients born in Asia or other non-US sites had significantly longer OS compared with US-born patients - a possible surrogate for hepatitis B infection. Treatment at an NCI-designated Comprehensive Cancer Center and at a hospital with a solid organ transplant program was associated with significantly better OS.

\section{Comparative Effectiveness}

The median survival in $\mathrm{Y}^{90}$ patients was 9 months (95\% CI, 1-41). In the PS-weighted population balanced across key clinical covariates (see supplemental eTable 2), $\mathrm{Y}^{90}$ was associated with an increased risk of death compared with TAE/TACE, with an ad- 


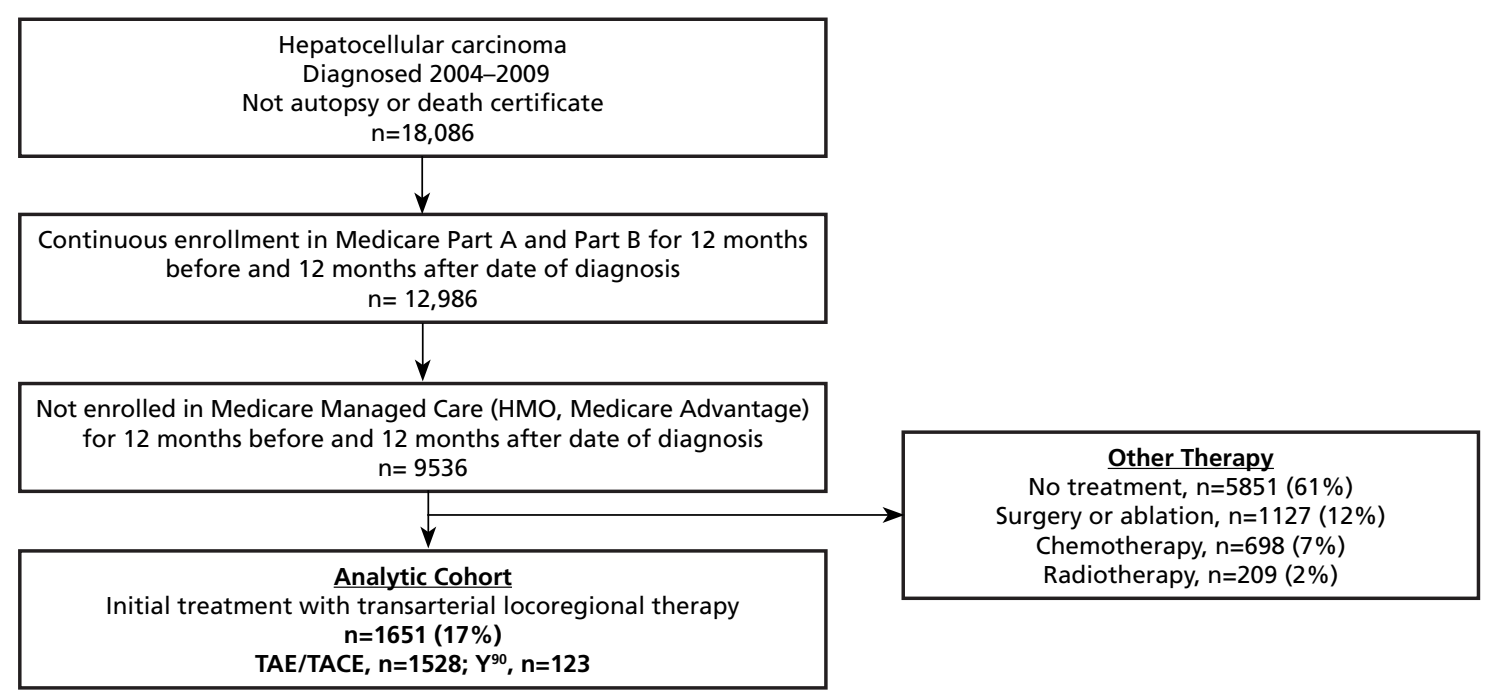

Figure 1 Cohort assembly.

Abbreviations: TACE, transarterial chemoembolization; TAE, transarterial embolization; $\mathrm{Y}^{90}$, yttrium ${ }^{90}$-labeled microsphere radioembolization.

justed hazard ratio (HR) of 1.39 (95\% CI, 1.02-1.90) (Figure 3$)$. The effect was more pronounced when restricting the comparison to just TACE, with an adjusted HR of 1.88 (95\% CI, 1.40-2.53; see supplemental eTable 3 ). We found little evidence that the greater risk of death with $\mathrm{Y}^{90}$ resulted from residual unmeasured confounding, because the trimming of patients treated contrary to prediction did not lead to an attenuation of the HR towards the null.

\section{Discussion}

In this large cohort of patients with newly diagnosed HCC, the survival estimate of 21 months for the true chemoembolization patients suggests that TACE effectiveness is retained across the broad range of health system settings where Medicare beneficiaries are treated in the United States, although treatment at a center with a solid organ transplant program or NCI Comprehensive Cancer Center status was associated with the best outcomes. However, we found that in the subgroup of TACE-treated patients whose disease was more extensive than is typically considered TACE-amenable (extrahepatic disease or multifocal disease with macrovascular invasion), immediate posttreatment mortality was very high, with $21 \%$ to $25 \%$ of patients dying within 90 days of treatment.

The expected duration of survival following TACE varies widely, because it is dependent on both the extent of cancer and the degree of underlying cirrhosis. ${ }^{32-34}$ In well-done ${ }^{35}$ randomized clinical trials using conventional (nonbead) TACE for unresectable HCC, median OS has been reported to be between 13.8 and 28.7 months. ${ }^{4,5,36}$ Better outcomes have been reported recently in patients with wellcompensated cirrhosis using the contemporary approach of doxorubicin-eluting bead TACE. ${ }^{37-39}$ Based on the existing data, the Standards of Practice Committee of the Society of Interventional Radiology has set the quality threshold of median survival following TACE at 20 months. ${ }^{8}$ Although we found that the median survival among Medicare beneficiaries treated with initial TACE met this quality threshold, 2 prior population-based observational studies also using SEER-Medicare data reported post-TACE median survivals of only less than 12 and 14 months. ${ }^{9,10}$ The first of these investigations was conducted in the 1990s, when only 4\% of patients were treated with TACE. Because use and techniques of TACE have evolved since the 1990s, it is likely that survival has also improved over this time. The more recent investigation of patients with $\mathrm{HCC}$ treated between 2000 and 2005 was designed to compare palliative approaches in the elderly; it intentionally excluded patients younger than 65 years and those receiving subsequent curative therapies. In contrast, we chose to retain younger patients eligible for Medicare based on disability in order to more broadly investigate the effectiveness of TACE in the United States. We also retained patients who underwent subsequent cura- 


\section{Table 1 Patient Characteristics and Association With Survival}

\begin{tabular}{|c|c|c|c|c|}
\hline Characteristic & $\begin{array}{l}\text { TACE + TAE } \\
(\mathrm{N}=1528)\end{array}$ & $\begin{array}{l}\text { TACE } \\
(n=577 ; 38 \%)\end{array}$ & $\begin{array}{l}\text { Multivariate } \mathrm{HR}^{\mathrm{a}} \\
(95 \% \mathrm{Cl})\end{array}$ & $P$ Value \\
\hline \multicolumn{5}{|l|}{ Treatment } \\
\hline TACE, no chemo code & - & & 1 & \\
\hline TACE, with chemo code & & & $0.78(0.69-0.89)$ & $<.001$ \\
\hline Median age, y (range) & $72(27-94)$ & $72(27-94)$ & - & - \\
\hline \multicolumn{5}{|l|}{ Age, y } \\
\hline$<65$ & $296(19 \%)$ & $108(19 \%)$ & 1 & \\
\hline $65-74$ & $635(42 \%)$ & $259(45 \%)$ & $1.02(0.85-1.22)$ & .82 \\
\hline $75+$ & $597(39 \%)$ & $210(36 \%)$ & $1.21(1.00-1.46)$ & 0.06 \\
\hline \multicolumn{5}{|l|}{ Sex } \\
\hline Male & $1045(68 \%)$ & $390(68 \%)$ & 1 & \\
\hline Female & $483(32 \%)$ & $187(32 \%)$ & $1.03(0.90-1.17)$ & .71 \\
\hline \multicolumn{5}{|l|}{ Race/Ethnicity } \\
\hline White & $1008(66 \%)$ & $374(65 \%)$ & 1 & \\
\hline African American & $136(9 \%)$ & $46(8 \%)$ & $0.94(0.75-1.18)$ & .60 \\
\hline Asian & $213(14 \%)$ & $92(16 \%)$ & $0.88(0.68-1.15)$ & .35 \\
\hline Hispanic/Other & $171(11 \%)$ & $65(11 \%)$ & $0.93(0.75-1.15)$ & .48 \\
\hline \multicolumn{5}{|l|}{ Place of birth } \\
\hline United States & $820(54 \%)$ & $278(48 \%)$ & 1 & \\
\hline Asia & $203(13 \%)$ & $85(15 \%)$ & $0.67(0.51-0.88)$ & .004 \\
\hline Other/Missing ${ }^{b}$ & $505(33 \%)$ & $214(37 \%)$ & $0.56(0.49-0.65)$ & $<.001$ \\
\hline Hepatitis $\mathrm{B}^{\mathrm{c}}$ & $147(10 \%)$ & $72(12 \%)$ & $0.89(0.70-1.13)$ & .34 \\
\hline Hepatitis Cc & $529(35 \%)$ & $211(37 \%)$ & $1.08(0.94-1.26)$ & .28 \\
\hline Alcohol $^{c}$ & $182(12 \%)$ & $73(13 \%)$ & $0.99(0.82-1.21)$ & .96 \\
\hline Otherc & $127(8 \%)$ & $51(9 \%)$ & $0.97(0.77-1.22)$ & .78 \\
\hline \multicolumn{5}{|l|}{ Modified Charlson score } \\
\hline 0 & $330(22 \%)$ & $111(19 \%)$ & 1 & \\
\hline 1 & $440(29 \%)$ & $181(31 \%)$ & $1.01(0.85-1.19)$ & .95 \\
\hline $2+$ & $758(50 \%)$ & $285(49 \%)$ & $1.06(0.90-1.24)$ & .50 \\
\hline \multicolumn{5}{|l|}{ Number of cirrhosis complications } \\
\hline 0 & $1161(76 \%)$ & $464(80 \%)$ & 1 & \\
\hline 1 & $240(16 \%)$ & $78(14 \%)$ & $1.37(1.16-1.62)$ & $<.001$ \\
\hline $2+$ & $127(8 \%)$ & $35(6 \%)$ & $1.51(1.18-1.94)$ & .002 \\
\hline \multicolumn{5}{|l|}{ Number of prediagnosis AFP claims } \\
\hline 0 & $639(42 \%)$ & $204(35 \%)$ & 1 & \\
\hline 1 & $456(30 \%)$ & $176(31 \%)$ & $0.79(0.69-0.92)$ & .002 \\
\hline $2+$ & $433(28 \%)$ & $197(34 \%)$ & $0.72(0.61-0.85)$ & $<.001$ \\
\hline \multicolumn{5}{|l|}{ Extent of tumor } \\
\hline Single, no vascular invasion & $639(42 \%)$ & $244(42 \%)$ & 1 & \\
\hline Multiple, no vascular invasion & $503(33 \%)$ & $207(36 \%)$ & $1.34(1.17-1.54)$ & $<.001$ \\
\hline Single, vascular invasion & $108(7 \%)$ & $38(7 \%)$ & $1.18(0.93-1.52)$ & .17 \\
\hline Multiple, vascular invasion & $130(8 \%)$ & $48(8 \%)$ & $1.62(1.30-2.01)$ & $<.001$ \\
\hline Extrahepatic extension or NOS & $148(10 \%)$ & $40(7 \%)$ & $1.75(1.40-2.19)$ & $<.001$ \\
\hline \multicolumn{5}{|l|}{ Maximum tumor size } \\
\hline$\leq 3 \mathrm{~cm}$ & $344(23 \%)$ & $150(26 \%)$ & 1 & \\
\hline $3-5 \mathrm{~cm}$ & $375(25 \%)$ & $151(26 \%)$ & $1.26(1.50-1.51)$ & .02 \\
\hline$>5 \mathrm{~cm}$ & $568(37 \%)$ & $202(35 \%)$ & $1.81(1.51-2.16)$ & $<.001$ \\
\hline Unknown & $241(16 \%)$ & $74(13 \%)$ & $1.70(1.36-2.13)$ & $<.001$ \\
\hline Teaching hospital $^{\mathrm{d}}$ & $1339(88 \%)$ & $508(89 \%)$ & $1.06(0.87-1.30)$ & .55 \\
\hline \multicolumn{5}{|l|}{ Hospital NCl designation in 2005} \\
\hline None & $1202(80 \%)$ & $471(82 \%)$ & 1 & \\
\hline Clinical & $36(2 \%)$ & $18(3 \%)$ & $1.18(0.78-1.79)$ & .42 \\
\hline Comprehensive & $272(18 \%)$ & $84(15 \%)$ & $0.75(0.63-0.89)$ & $<.001$ \\
\hline Hospital with solid organ transplant & $1076(71 \%)$ & $422(74 \%)$ & $0.72(0.62-0.85)$ & $<.001$ \\
\hline \multicolumn{5}{|l|}{ Hospital volume in prior $12 \mathrm{mo}$} \\
\hline$<5$ & $802(52 \%)$ & $258(45 \%)$ & 1 & \\
\hline $5-20$ & $420(27 \%)$ & $165(29 \%)$ & $0.92(0.79-1.07)$ & .26 \\
\hline$>20$ & $306(20 \%)$ & $154(27 \%)$ & $0.88(0.73-1.07)$ & .19 \\
\hline
\end{tabular}

Abbreviations: AFP, $\alpha$-fetoprotein; chemo, chemotherapy; HR, hazard ratio; NOS, not otherwise specified; TACE, transarterial chemoembolization. aHR adjusted for variables shown and census track median income, SEER region.

b360 patients had missing place of birth and 145 patients were non--US, non--Asian born.

'Causes are not mutually exclusive. HR referent $=$ no.

dBecause of missing data, hospital variables do not sum to 1528 . 
Table 2 Survival Estimates by Patient Subgroup After TACE

\begin{tabular}{|c|c|c|c|c|c|c|}
\hline \multicolumn{3}{|c|}{ Patient Subgroup } & \multicolumn{4}{|c|}{$\begin{array}{l}\text { TACE With Chemotherapy Group } \\
\text { Overall Survival Estimates }\end{array}$} \\
\hline Tumor Extent & $\begin{array}{l}\text { Liver } \\
\text { Comorbidity }\end{array}$ & $\begin{array}{l}\text { AFP } \\
\text { Screening }\end{array}$ & $\mathbf{N}$ & $\begin{array}{l}\text { Median Survival, } \\
\text { mo } \\
(95 \% \mathrm{Cl})\end{array}$ & $\begin{array}{l}\text { 90-day } \\
\text { n (\%) }\end{array}$ & $\begin{array}{l}\text { 24-month } \\
\text { n (\%) }\end{array}$ \\
\hline \multirow{5}{*}{$\begin{array}{l}\text { Single, no vascular } \\
\text { invasion }\end{array}$} & All & All & 244 & $24(21-28)$ & $231(95 \%)$ & $112(49 \%)$ \\
\hline & No & No & 79 & $20(17-24)$ & $71(90 \%)$ & $28(38 \%)$ \\
\hline & No & Yes & 112 & $29(25-41)$ & $109(97 \%)$ & $63(60 \%)$ \\
\hline & Yes & No & $<11$ & $11(1-33)$ & $<11$ & $<11$ \\
\hline & Yes & Yes & c & $23(12-N A)$ & c & c \\
\hline \multirow{5}{*}{$\begin{array}{l}\text { Multiple, no vascular } \\
\text { invasion }\end{array}$} & All & All & 207 & $21(16-25)$ & $191(92 \%)$ & $90(46 \%)$ \\
\hline & No & No & 57 & $16(8-24)$ & $51(89 \%)$ & $21(37 \%)$ \\
\hline & No & Yes & 109 & $25(20-31)$ & $100(92 \%)$ & $55(54 \%)$ \\
\hline & Yes & No & 12 & $11.5(7-23)$ & $12(100 \%)$ & $<11$ \\
\hline & Yes & Yes & 29 & $23(15-39)$ & $28(97 \%)$ & $13(48 \%)$ \\
\hline Single, vascular invasion & All & All & 38 & $19.5(12-38)$ & $33(87 \%)$ & $14(42 \%)$ \\
\hline $\begin{array}{l}\text { Multiple, vascular } \\
\text { invasion }\end{array}$ & All & All & 48 & $11(5-20)$ & $38(79 \%)$ & $14(33 \%)$ \\
\hline \multirow[t]{4}{*}{ Any $^{\text {b }}$, vascular invasion } & No & No & 30 & $14.5(12-29)$ & $25(83 \%)$ & $<11$ \\
\hline & No & Yes & 44 & $19(8-46)$ & $39(89 \%)$ & $18(45 \%)$ \\
\hline & Yes & No & $<11$ & $3.5(2-5)$ & $<11$ & 0 \\
\hline & Yes & Yes & $<11$ & $5.5(0-10)$ & $<11$ & $<11$ \\
\hline $\begin{array}{l}\text { Extrahepatic extension } \\
\text { or NOS }\end{array}$ & All & All & 40 & $13.5(5-18)$ & $30(75 \%)$ & $<11$ \\
\hline
\end{tabular}

Abbreviations: AFP, $\alpha$-fetoprotein; chemo, chemotherapy; NA, not applicable; NOS, not otherwise specified; TACE, transarterial chemoembolization. a22 patients were censored at 24 months. Cells with $<11$ patients suppressed to preserve confidentiality.

${ }^{b}$ Because of small numbers, patients with single and multiple tumors with any vascular invasion were combined for analysis by AFP and liver comorbidity. Also because of small sample size, further subgroup analysis was not performed on patients with extrahepatic spread.

'Number suppressed to preserve confidentiality.

tive surgery, transplant, and ablative procedures, because excluding these patients underestimates the effect of TACE by selectively excluding those with the best response. Because of these differences, we do not believe these data to be conflicting; rather, our report expands on this prior work by providing survival estimates across a broader range of treatment scenarios.

Because registry data do not contain laboratory data or performance status, we could not evaluate outcomes by HCC-relevant clinical categories of Child-Pugh or Barcelona Clinic Liver Cancer (BCLC) stage. To address this limitation, we used surrogates for the components of BCLC stage (extent of cancer, performance status, and Child-Pugh score $)^{40}$ to refine our survival estimates. We used the cancer-specific tumor extent from SEER that includes macrovascular invasion. However, the predominantly clinical staging paradigm of HCC differs greatly from other cancers. Concordance between registrarreported vascular invasion has not been evaluated to the best of our knowledge, but may be poor. Codes for complications of cirrhosis before diagnosis were used as a marker of the extent of cirrhosis. As this ap- proach relies on the thoroughness of physician coding, these codes likely underestimate the extent of cirrhosis and limit the direct clinical applicability of the estimates provided for patients with and without liver comorbidity in this analysis. Prediagnosis AFP screening was chosen given prior evidence of cancer screening as a marker of frailty, ${ }^{41}$ although AFP is likely a marker for multiple factors associated with improved outcomes, including possible earlier detection with a lower burden of disease and engagement with the health care system. Although these means of stratifying patients is less granular than validated HCC staging systems, each component was strongly associated with survival.

Fifteen percent of patients treated with TACE in this cohort had disease beyond that for which TACE is currently recommended, ${ }^{7}$ including multifocal disease with macrovascular invasion and extrahepatic disease. In this subgroup of patients with advanced cancer, 90 -day mortality was very high: $21 \%$ to $25 \%$. Because untreated patients are inherently different, we did not compare outcomes between treated and untreated patients to explore the extent to which 
Sanoff et al

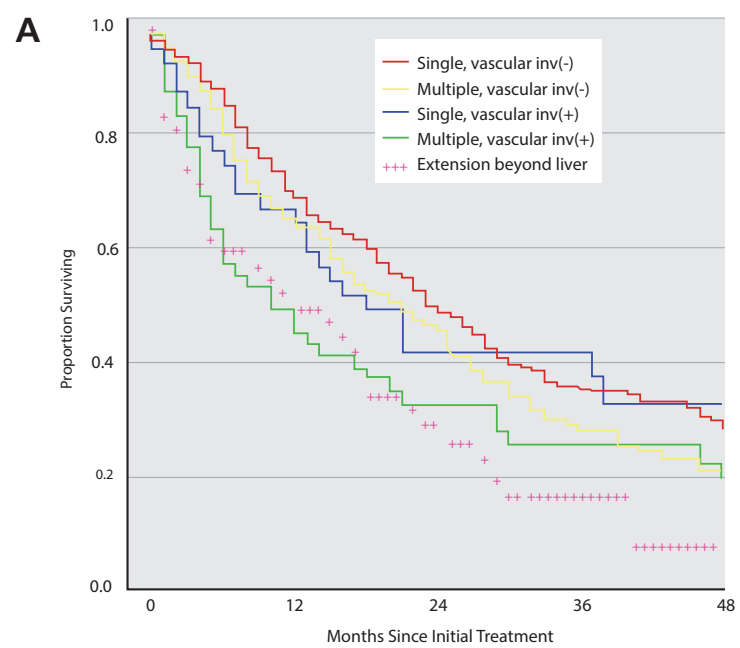

B
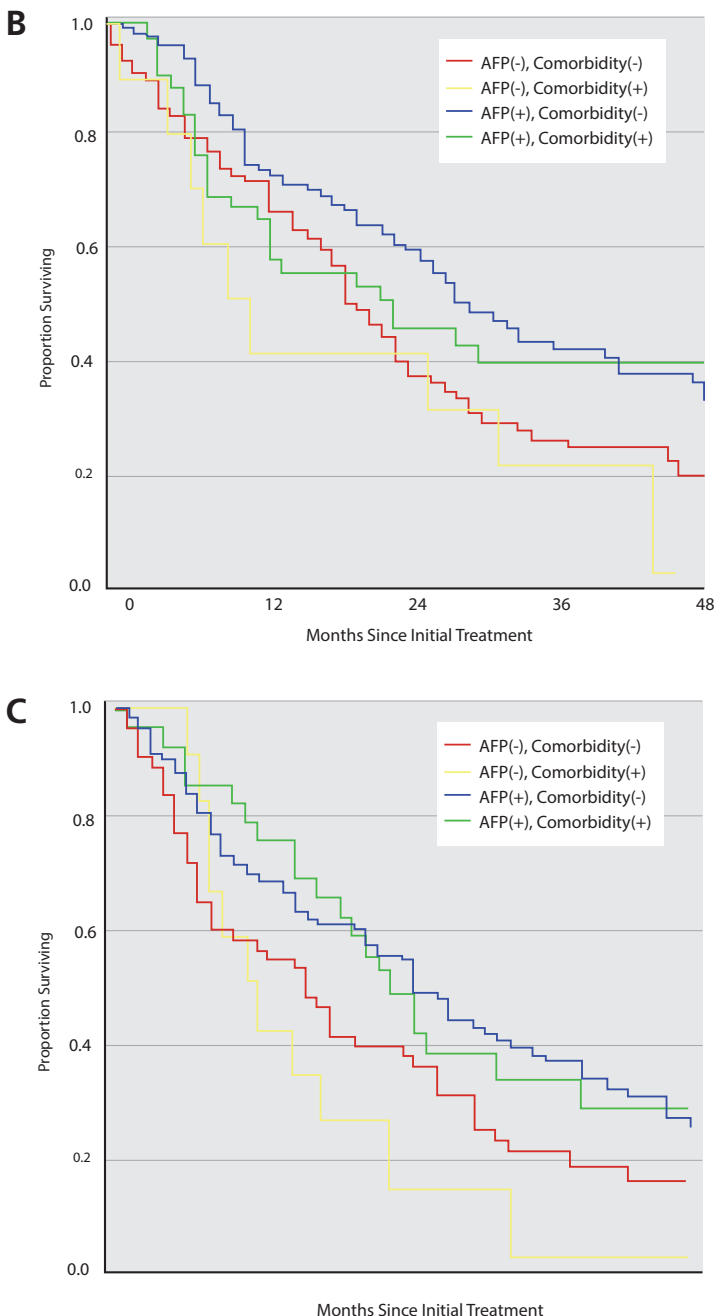

Figure 2 Kaplan-Meier estimates of survival following transarterial chemoembolization (TACE). Survival estimates for patients with documented chemotherapy administration at time of TACE procedure for (A) the entire cohort $(n=577)$ by tumor extent, (B) single tumors without vascular invasion $(n=244)$, and (C) multiple tumors without vascular invasion $(n=207)$ by $\alpha$-fetoprotein (AFP) screening and liver comorbidity.

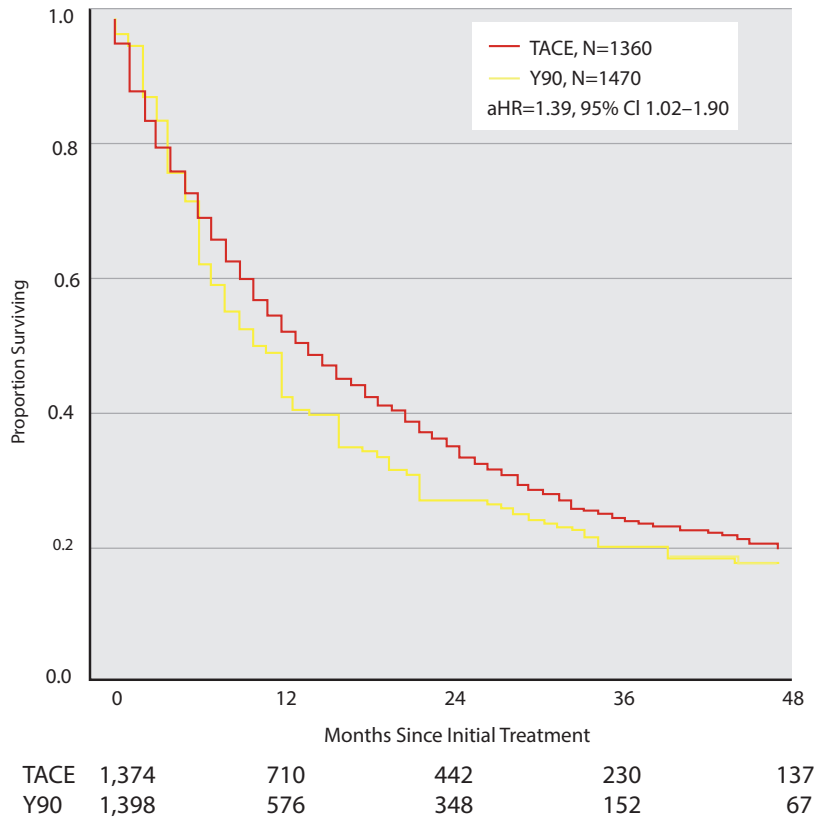

Figure 3 Kaplan-Meier estimates of survival by treatment. Survival estimates for TACE and $Y^{90}$ radioembolization are shown for the propensity score-weighted population.

Abbreviations: aHR, adjusted hazard ratio; TACE, transarterial chemoembolization; $\mathrm{Y}^{90}$, yttrium ${ }^{90}$-labeled microsphere radioembolization.

this early mortality was the result of hepatic decompensation after treatment or ineffective treatment in terminally ill individuals. In this sicker group of patients, it would be particularly relevant to know more detail about the technical aspects of TACE, specifically whether the procedure was performed using superselective techniques that minimize the damage to nonneoplastic liver, or whether a more extensive embolization was performed. Unfortunately, this quality metric cannot be ascertained from embolization codes in any reliable fashion. However, if patients with poorly compensated cirrhosis were treated with less selective embolization, this might account for the poor outcomes of TACE in this advanced-disease group. Without this information, we cannot definitively conclude whether it is all TACE that does not benefit patients with advanced disease, or merely poor-quality TACE.

Patients with a poor performance status, diffuse infiltrative cancer, Child-Pugh $\mathrm{C}$ cirrhosis, and Child-Pugh B cirrhosis with portal vein thrombosis all have an exceptionally poor prognosis even with TACE or $\mathrm{Y}^{90} .11,32,33$ Unfortunately, few data are available to help determine whether LRT improves outcomes in this high-risk group, or whether they are 
better served by sorafenib or supportive care. Studies designed to evaluate if TACE and/or $\mathrm{Y}^{90}$ improve outcomes over supportive care or sorafenib (eg, ClinicalTrials.gov identifier: NCT01887717; Y90 vs sorafenib in patients with portal vein occlusion) are difficult to complete but of paramount importance.

Our exploration of the comparative effectiveness of $\mathrm{Y}^{90}$-radioembolization versus TACE was limited by a small number of $\mathrm{Y}^{90}$-treated patients; however, we found no suggestion that $\mathrm{Y}^{90}$ offered a survival advantage over TACE. The median survival of 9 months was well below what has been reported for patients with compensated cirrhosis after $\mathrm{Y}^{90}$ radioembolization, ${ }^{11,12,15,21,32}$ and may simply reflect use of $\mathrm{Y}^{90}$ in patients with more advanced liver disease and a larger burden of cancer.

Our study also shows that, although registrylinked claims data allow for a broad overview of outcomes of HCC treatment, the lack of HCC-relevant staging - specifically laboratory parameters and components of Child-Pugh score-markedly limits the feasibility of a nuanced study. Because HCC is one of a few cancers with a rising incidence and mortality in the United States, ${ }^{42}$ efforts should be made to incorporate laboratory parameters relevant to HCC staging into mandatory cancer registry reporting. These efforts would improve the ability to study the comparative safety and effectiveness of emerging therapies for this deadly disease.

\section{Acknowledgments}

Research reported in this publication was supported by the National Cancer Institute of the $\mathrm{Na}$ tional Institutes of Health under Award Number K07CA160722. The content is solely the responsibility of the authors and does not necessarily represent the official views of the National Institutes of Health. This study used the linked SEER-Medicare database. The interpretation and reporting of these data are the sole responsibility of the authors. The authors acknowledge the efforts of the Applied Research Program, NCI; the Office of Research, Development and Information, CMS; Information Management Services (IMS), Inc.; and the SEER Program tumor registries in the creation of the SEER-Medicare database.

\section{References}

1. Howlader N, Noone AM, Krapcho M, et al. SEER Cancer Statistics Review, 1975-2011, National Cancer Institute. Bethesda, MD, http:// seer.cancer.gov/csr/1975_2011/, based on November 2013 SEER data submission, posted to the SEER web site, April 2014.

2. El-Serag HB. Hepatocellular carcinoma. N Engl J Med 2011;365:11181127.

3. Davila JA, Morgan RO, Shaib Y, et al. Hepatitis C infection and the increasing incidence of hepatocellular carcinoma: a population-based study. Gastroenterology 2004;127:1372-1380.

4. Llovet JM, Real MI, Montana X, et al. Arterial embolisation or chemoembolisation versus symptomatic treatment in patients with unresectable hepatocellular carcinoma: a randomised controlled trial. Lancet 2002;359:1734-1739.

5. Lo CM, Ngan H, Tso WK, et al. Randomized controlled trial of transarterial lipiodol chemoembolization for unresectable hepatocellular carcinoma. Hepatology 2002;35:1164-1171.

6. Llovet JM, Bruix J. Systematic review of randomized trials for unresectable hepatocellular carcinoma: chemoembolization improves survival. Hepatology 2003;37:429-442.

7. Bruix J, Sherman M; American Association for the Study of Liver Diseases. Management of hepatocellular carcinoma: an update. Hepatology 2011;53:1020-1022.

8. Brown DB, Nikolic B, Covey AM, et al. Quality improvement guidelines for transhepatic arterial chemoembolization, embolization, and chemotherapeutic infusion for hepatic malignancy. J Vasc Interv Radiol 2012;23:287-294.

9. El-Serag HB, Siegel AB, Davila JA, et al. Treatment and outcomes of treating of hepatocellular carcinoma among Medicare recipients in the United States: a population-based study. J Hepatol 2006;44:158-166.

10. Davila JA, Duan Z, McGlynn KA, El-Serag HB. Utilization and outcomes of palliative therapy for hepatocellular carcinoma: a population-based study in the United States. J Clin Gastroenterol 2012;46:71-77.

11. Sangro B, Salem R, Kennedy A, et al. Radioembolization for hepatocellular carcinoma: a review of the evidence and treatment recommendations. Am J Clin Oncol 2011;34:422-431.

12. Sangro B, Carpanese L, Cianni R, et al. Survival after yttrium-90 resin microsphere radioembolization of hepatocellular carcinoma across Barcelona clinic liver cancer stages: a European evaluation. Hepatology 2011;54:868-878.

13. Kulik LM, Carr BI, Mulcahy MF, et al. Safety and efficacy of $90 \mathrm{Y}$ radiotherapy for hepatocellular carcinoma with and without portal vein thrombosis. Hepatology 2008;47:71-81.

14. Salem R, Lewandowski RJ, Mulcahy MF, et al. Radioembolization for hepatocellular carcinoma using Yttrium-90 microspheres: a comprehensive report of long-term outcomes. Gastroenterology 2010;138:52-64.

15. Hilgard P, Hamami M, Fouly AE, et al. Radioembolization with yttrium-90 glass microspheres in hepatocellular carcinoma: European experience on safety and long-term survival. Hepatology 2010;52:1741-1749.

16. Carr BI, Kondragunta V, Buch SC, Branch RA. Therapeutic equivalence in survival for hepatic arterial chemoembolization and yttrium 90 microsphere treatments in unresectable hepatocellular carcinoma: a twocohort study. Cancer 2010;116:1305-1314.

17. Lewandowski RJ, Kulik LM, Riaz A, et al. A comparative analysis of transarterial downstaging for hepatocellular carcinoma: chemoembolization versus radioembolization. Am J Transplant 2009;9:1920-1928.

18. Lance C, McLennan G, Obuchowski N, et al. Comparative analysis of the safety and efficacy of transcatheter arterial chemoembolization and yttrium-90 radioembolization in patients with unresectable hepatocellular carcinoma. J Vasc Interv Radiol 2011;22:1697-1705.

19. Kooby DA, Egnatashvili V, Srinivasan S, et al. Comparison of yttrium-90 radioembolization and transcatheter arterial chemoembolization for the treatment of unresectable hepatocellular carcinoma. J Vasc Interv Radiol 2010;21:224-230.

20. Moreno-Luna LE, Yang JD, Sanchez W, et al. Efficacy and safety of transarterial radioembolization versus chemoembolization in patients with hepatocellular carcinoma. Cardiovasc Intervent Radiol 2013;36:714-723.

21. Mazzaferro V, Sposito $C$, Bhoori $S$, et al. Yttrium- 90 radioembolization for intermediate-advanced hepatocellular carcinoma: a phase 2 study. Hepatology 2013;57:1826-1837.

22. SEER-Medicare Linked Database. National Cancer Institute Web site. Available at: http://appliedresearch.cancer.gov/seermedicare/. Accessed April 9, 2014. 
23. Warren JL, Klabunde CN, Schrag D, et al. Overview of the SEERMedicare data: content, research applications, and generalizability to the United States elderly population. Med Care 2002;40(8 Suppl):IV-3-18.

24. Ulahannan SV, Duffy AG, McNeel TS, et al. Earlier presentation and application of curative treatments in hepatocellular carcinoma. Hepatology 2014;60:1637-1644.

25. Davila JA, Morgan RO, Richardson PA, et al. Use of surveillance for hepatocellular carcinoma among patients with cirrhosis in the United States. Hepatology 2010;52:132-141.

26. Richardson P, Henderson L, Davila JA, et al. Surveillance for hepatocellular carcinoma: development and validation of an algorithm to classify tests in administrative and laboratory data. Dig Dis Sci 2010;55:3241-3251.

27. Faurot KR, Jonsson Funk M, et al. Using claims data to predict dependency in activities of daily living as a proxy for frailty. Pharmacoepidemiol Drug Saf 2015;24:59-66.

28. Klabunde CN, Potosky AL, Legler JM, Warren JL. Development of a comorbidity index using physician claims data. J Clin Epidemiol 2000;53:1258-1267.

29. Warren JL, Harlan LC, Fahey A, et al. Utility of the SEER-Medicare data to identify chemotherapy use. Med Care 2002;40:IV-55-61.

30. Sturmer T, Rothman KJ, Glynn RJ. Insights into different results from different causal contrasts in the presence of effect-measure modification. Pharmacoepidemiol Drug Saf 2006;15:698-709.

31. Sturmer T, Rothman KJ, Avorn J, Glynn RJ. Treatment effects in the presence of unmeasured confounding: dealing with observations in the tails of the propensity score distribution-a simulation study. Am J Epidemiol 2010;172:843-854

32. Salem R, Lewandowski RJ, Mulcahy MF, et al. Radioembolization for hepatocellular carcinoma using Yttrium-90 microspheres: a comprehensive report of long-term outcomes. Gastroenterology 2010;138:52-64.

33. Lewandowski RJ, Mulcahy MF, Kulik LM, et al. Chemoembolization for hepatocellular carcinoma: comprehensive imaging and survival analysis in a 172-patient cohort. Radiology 2010;255:955-965
34. Raoul JL, Sangro B, Forner A, et al. Evolving strategies for the management of intermediate-stage hepatocellular carcinoma: available evidence and expert opinion on the use of transarterial chemoembolization. Cancer Treat Rev 2011;37:212-220.

35. Rose SC, Kikolski SG, Gish RG, et al. Society of Interventional Radiology critique and commentary on the Cochrane report on transarterial chemoembolization. Hepatology 2013;57:1675-1676.

36. Doffoel $M$, Bonnetain $F$, Bouche $O$, et al. Multicentre randomised phase III trial comparing tamoxifen alone or with transarterial lipiodol chemoembolisation for unresectable hepatocellular carcinoma in cirrhotic patients (Federation Francophone de Cancerologie Digestive 9402). Eur J Cancer 2008;44:528-538.

37. Varela M, Real MI, Burrel M, et al. Chemoembolization of hepatocellular carcinoma with drug eluting beads: efficacy and doxorubicin pharmacokinetics. J Hepatol 2007;46:474-481

38. Dhanasekaran R, Kooby DA, Staley CA, et al. Comparison of conventional transarterial chemoembolization (TACE) and chemoembolization with doxorubicin drug eluting beads (DEB) for unresectable hepatocelluar carcinoma (HCC). J Surg Oncol 2010;101:476-480

39. Martin RC 2nd, Rustein L, Perez Enguix D, et al. Hepatic arterial infusion of doxorubicin-loaded microsphere for treatment of hepatocellular cancer: a multi-institutional registry. J Am Coll Surg 2011;213:493-500.

40. Llovet JM, Bru C, Bruix J. Prognosis of hepatocellular carcinoma: the BCLC staging classification. Semin Liver Dis 1999;19:329-338.

41. Faurot KR, Jonsson Funk M, et al. Using claims data to predict dependency in activities of daily living as a proxy for frailty. Pharmacoepidemiol Drug Saf 2015;24:59-66.

42. Edwards BK, Ward E, Kohler BA, et al. Annual report to the nation on the status of cancer, 1975-2006, featuring colorectal cancer trends and impact of interventions (risk factors, screening, and treatment) to reduce future rates. Cancer 2010;116:544-573.

\section{See JNCCN.org for supplemental online content.}

